\title{
Developmental Psychology, Adult
}

National Cancer Institute

\section{Source}

National Cancer Institute. Developmental Psychology, Adult. NCI Thesaurus. Code C18738.

Developmental psychology research focusing on the adult years. 